\title{
Qualidade de inflorescências de Heliconia stricta e Heliconia bihai produzidas sob adubação química e orgânica
}

\author{
ANDREZZA DA SILVA MACHADO NETO(2), JANIE MENDES JASMIM(3), JOSÉ TARCÍSIO LIMA THIÉBAUT(4), \\ PRISCILLA BRITES XAVIER(5)
}

\begin{abstract}
RESUMO
O objetivo deste trabalho foi avaliar a qualidade das inflorescências de Heliconia stricta e Heliconia bihai cultivadas a pleno sol, com irrigação, sob três tratamentos: adubação química, orgânica e sem adubação. Ao longo do ciclo produtivo, duzentas e oitenta e cinco inflorescências de H. bihai, em 15 meses e 142 inflorescências de $H$. stricta, em nove meses, foram avaliadas pelo método de amostragem simples ao acaso. A qualidade foi avaliada através da distribuição das inflorescências em cinco classes (C), de acordo com o padrão de qualidade do atacado, e através de duas classes (A e B) de aceitação do varejo. Em H. bihai, o tratamento químico produziu maior número de inflorescências com melhor qualidade. $H$. stricta produziu maior número de inflorescências, de melhor qualidade, sem adubação.

Palavras-chave: Heliconia, Heliconiaceae, flores tropicais, qualidade da inflorescência.
\end{abstract}

\section{ABSTRACT}

Quality of inflorescences of Heliconia stricta and Heliconia bihai yielded under chemical and organic fertilization

\begin{abstract}
The objective of this work was to assess chemical and organic fertilizations on the quality of inflorescences of Heliconia bihai and Heliconia stricta grown under full sunlight under irrigation and three fertilization treatments: chemical, organic and without fertilization. Throughout the productive cycle, two hundred and eighty five inflorescences of $H$. bihai, in 15 months, and 142 inflorescences of $H$. stricta, in nine months, were evaluated using the simple random sampling method. The quality was evaluated by distributing the inflorescences into five classes (C), according to their wholesale quality standard, and into two classes (A and B) of retail market acceptance. In H. bihai, the chemical treatment yielded the largest number of inflorescences with best quality. H. stricta yielded the largest number of inflorescences of best quality without fertilizers.
\end{abstract}

Keywords: Heliconia, Heliconiaceae, tropical flowers, inflorescence quality.

\section{INTRODUÇÃO}

As flores tropicais são responsáveis por uma grande parcela da comercialização de plantas ornamentais, tanto no mercado nacional quanto internacional. Segundo o IBRAFLOR (2001), o mercado nacional, antes baseado em plantas e flores tradicionais como rosas, crisântemos, gladíolos e violetas, passou a se interessar por produtos diferenciados, tornando o momento oportuno para o incremento na produção de espécies tropicais. Entre estas espécies, estão as do gênero Heliconia, o único gênero da família Heliconiaceae, uma das oito famílias da ordem Zingiberales (BERRY e KRESS, 1991).

As helicônias são plantas herbáceas que podem ser cultivadas tanto a pleno sol quanto a meia sombra. Apresentam perspectivas promissoras como flores de corte porque reúnem beleza, exoticidade, coloração contrastante, com intenso brilho em suas brácteas e longevidade póscolheita (CASTRO, 1993; CASTRO e GRAZIANO, 1997).

CASTRO et al. (2005) mencionam os problemas existentes na cadeia produtiva destas flores devido ao número ainda insuficiente de pesquisas tecnológicas e à inexistência de informações precisas sobre aspectos relevantes do cultivo. Existe uma grande variação no manejo das helicônias, principalmente no que se refere à adubação mineral. Há registros de cultivos comerciais usando relações de N-P-K em diferentes proporções.

Recomenda-se a utilização da fórmula N-P-K 18:6:12, com aplicação de $3 \mathrm{~kg} \mathrm{~m}^{-2}$ parcelado em duas ou três vezes durante o ano, para o cultivo da Heliconia psittacorum 'Andromeda' e H. psittacorum 'Golden Torch' (BROSCHAT e DONSELMAN, 1983; BROSCHAT, al., 1984). Estes mesmos autores citam que baixas taxas de fertilizantes resultam na redução da produção de flores sob condição de pleno sol. O rápido desenvolvimento vegetativo, seguido pelo florescimento, pode ser obtido, segundo LAMAS (2001), mediante a utilização da fórmula N-P-K 15-15-15 na dosagem de $150 \mathrm{~g}$ por cova, aplicada três a quatro vezes durante o ano, sem que a qualidade floral seja afetada.

No que se refere ao uso de adubos orgânicos como única fonte nutricional, poucas são as referências literárias encontradas para a adubação de helicônias. CASTRO (1995) sugere, sem mencionar os efeitos qualitativos da adubação sobre a produção de inflorescências, o uso de esterco de

\footnotetext{
(1) Recebido em 12/11/2009 e aceito para publicação em 08/08/2011.

(2) Bolsista de IC, Laboratório de Fitotecnia (LFIT), Centro de Ciências e Tecnologias Agropecuárias (CCTA) Universidade Estadual do Norte Fluminense Darcy Ribeiro (UENF), Av. Alberto Lamego, 2000 - Pq. Califórnia, Campos dos Goytacazes, RJ, Brasil - CEP 28013-602. E-mail: andrezzasmachado@yahoo.com.br. Autor para correspondência.

(3) Professora associada, LFIT/CCTA/UENF.

(4) Professor associado, Laboratório de Engenharia Agrícola (LEAG)/CCTA/UENF.

${ }^{(5)}$ Bolsista de IC, LFIT/CCTA/UENF.
} 
curral curtido (40 $\mathrm{L} \mathrm{m}^{-2}$ de canteiro), incorporando-o ao solo juntamente com folhas decompostas. Ademais, o uso exclusivo de cama de frango, na proporção de $10 \mathrm{~L}$ touceira $^{-1}$ ano $^{-1}$, também é uma forma alternativa de adubo para a produção orgânica de Heliconia bihai (OLIVEIRA et al., 2006b).

Considerando a carência de informações técnicas sobre o efeito da adubação na qualidade das inflorescências de helicônias e a importância que tal espécie tem no cenário da floricultura nacional e internacional, este trabalho teve como objetivo avaliar a qualidade das inflorescências de Heliconia stricta e Heliconia bihai produzidas sob adubação química e orgânica a pleno sol.

\section{MATERIAL E MÉTODOS}

Os experimentos foram instalados em março de 2004, na Estação Experimental do Centro de Ciências e Tecnologias Agropecuárias (CCTA), da Universidade Estadual do Norte Fluminense Darcy Ribeiro (Uenf), localizada no município de Campos dos Goytacazes (RJ), situado a $21^{\circ} 45^{\prime} 15^{\prime}$ ' sul e $41^{\circ} 19^{\prime} 26^{\prime}$ " oeste e 14 metros de altitude (MIRANDA et al., 2005). A região, segundo Köppen, é classificada como tropical chuvosa, clima de bosque (Am). Os dados meteorológicos relativos ao período de condução do experimento foram obtidos na estação meteorológica da Estação Experimental de Campos - Pesagro, em Campos dos Goytacazes, RJ (Tabela 1).

As mudas de ambas as espécies de helicônias foram retiradas de plantas adultas, pela divisão dos rizomas, deixando-se três hastes de 20 a $30 \mathrm{~cm}$ de altura em cada torrão, de aproximadamente $15 \mathrm{~cm}$ de largura e comprimento. Em seguida, foram transplantadas para o local definitivo do experimento.

O cultivo das Heliconia stricta e Heliconia bihai foi estabelecido no campo, em covas de 40x 40x40 cm, após limpeza e aração da área, utilizando o espaçamento de $1,0 \mathrm{x}$ 1,0 m, em Cambissolo Háplico, textura argilo-siltosa, cujas características químicas na camada de $0-20 \mathrm{~cm}$ da área experimental foram as seguintes: $\mathrm{pH} 5,6 ; 37,1 \mathrm{~g} \mathrm{~kg}^{-1}$ de M. O.; $9 \mathrm{mg} \mathrm{kg}^{-1}$ de P; $136 \mathrm{mg} \mathrm{kg}^{-1}$ de K; $5,1 \mathrm{cmol} \mathrm{kg}^{-1}$ de Ca; 3,7 $\mathrm{cmol}_{\mathrm{c}} \mathrm{kg}^{-1}$ de $\mathrm{Mg}$; e 5,0 $\mathrm{cmol}_{\mathrm{c}} \mathrm{kg}^{-1} \mathrm{de} \mathrm{H}+\mathrm{Al}$.

Os adubos químicos e orgânicos utilizados foram compostos, respectivamente, por: $114 \mathrm{~g}$ de sulfato de amônio $+150 \mathrm{~g}$ de superfosfato simples $+33 \mathrm{~g}$ de nitrato de potássio; e $1600 \mathrm{~g}$ de cama de frango $+200 \mathrm{~mL}$ de vinhoto, acrescido de $30 \mathrm{~g}$ de fosfato de Araxá. As características químicas dos adubos orgânicos foram as seguintes: Cama de frango - 26,43 $\mathrm{g} \mathrm{Kg}^{-1}$ de $\mathrm{N}, 35,56 \mathrm{~g} \mathrm{Kg}^{-1}$ de $\mathrm{P}_{2} \mathrm{O}_{5}$ e $13,44 \mathrm{~g} \mathrm{Kg}^{-1}$ de $\mathrm{K}_{2} \mathrm{O}$; Fosfato de Araxá - 273,45 $\mathrm{g}$ $\mathrm{Kg}^{-1}$ de $\mathrm{P}_{2} \mathrm{O}_{5}$; e Vinhoto $-5,84 \mathrm{Kg} \mathrm{m}^{-3}$ de $\mathrm{K}_{2} \mathrm{O}$. Assim, a adubação química e a adubação orgânica foram efetuadas de modo a fornecerem, respectivamente, por cova, a cada aplicação: 25 g de N, 13 g de P e 13 g de K; e 42 g de N, 28 $\mathrm{g}$ de $\mathrm{P}$ e $18 \mathrm{~g}$ de $\mathrm{K}$. Os adubos foram aplicados a cada três meses, distribuídos ao redor das touceiras de helicônias, num raio de aproximadamente $20 \mathrm{~cm}$ de distância da planta, com posterior incorporação.

A necessidade de irrigação foi avaliada, diariamente, por meio de seis sensores do tipo Sistema Gasoso de Controle da Irrigação (Irrigas ${ }^{\circledR}$ ), distribuídos na área dos experimentos. O irrigas ${ }^{\circledR}$ é constituído de uma cápsula porosa, posicionada entre $30-40 \mathrm{~cm}$ de profundidade próxima ao sistema radicular de algumas plantas, conectada através de um tubo plástico transparente a um pequeno tubo rígido também transparente $(5 \mathrm{~cm}$ comprimento) . A leitura da umidade do solo é feita imergindo pequeno tubo rígido transparente num frasco de água. Se a água não entrar no tubo é porque a cápsula porosa está saturada de umidade, neste caso, o solo ainda está úmido e a irrigação ainda não é necessária. A entrada de água no pequeno tubo rígido transparente é indicativa de solo seco, os poros da cápsula estão abertos, deixando o ar fluir livremente. Após esta constatação, o solo deve ser logo irrigado. O sistema de irrigação utilizado foi por gotejamento localizado em cada cova, utilizando dois gotejadores por planta, com vazão de $4,5 \mathrm{~L} \mathrm{~h}^{-1}$.

O estudo foi conduzido utilizando o método de amostragem simples ao acaso para duas espécies de helicônia. Foram realizadas amostragens de campo em duas áreas: amostragem 1- área com Heliconia biha; e amostragem 2- área com Heliconia stricta.

As plantas selecionadas ao acaso foram mantidas a pleno sol para estudo do número de inflorescências em três situações diferentes, correspondendo aos tratamentos: 1adubação química; 2 - adubação orgânica; e 3 - testemunha (sem adubação). O stand foi composto por 162 plantas, 108 eram da espécie $H$. stricta e $54 H$. bihai, sendo amostradas seis plantas por espécie, em cada tratamento $(6 \times 2 \times 3)$, totalizando 36 parcelas úteis.

A produção de hastes florais foi observada, semanalmente, de novembro de 2004 a setembro de 2006 para $H$. bihai e de fevereiro de 2005 a junho de 2006 para H. stricta, por ocorrência do florescimento da parcela útil. A colheita foi realizada pela manhã (8-10h), respeitando o ponto de colheita de três brácteas abertas (Figura 1), procedendo ao corte em bisel do pseudocaule, próximo ao nível do solo e feita a eliminação das folhas, mantendo cerca de $10 \mathrm{~cm}$ dos pecíolos das duas ou três folhas mais próximas da inflorescência, acima dela.

Em virtude de características intrínsecas de cada espécie, obtiveram-se diferentes períodos de produção, sendo avaliadas duzentas e oitenta e cinco inflorescências, que ocorreram em 15 meses de produção da espécie $H$. bihai, e 142 inflorescências de $H$. stricta, que ocorreram em nove meses de produção.

As amostras foram dimensionadas com o objetivo de concluir acerca da representatividade de um número infinito de inflorescências. Foram utilizados o nível de $5 \%$ de probabilidade e um desvio de $5 \%$ para mais e para menos da média amostral.

As inflorescências foram distribuídas em cinco classes C, Tabela 2, conforme o número de defeitos que poderiam ser encontrados, considerando os padrões de qualidade ornamental para venda no atacado Veiling (Holambra-SP) e as características mínimas estabelecidas pelo Ibraflor para H. bihai (IBRAFLOR, 2000). Neste sentido, as classes $\mathrm{C} 1, \mathrm{C} 2, \mathrm{C} 3, \mathrm{C} 4$ e $\mathrm{C} 5$ representam, respectivamente, inflorescências sem defeitos, com defeitos leves, com defeitos medianos, com defeitos graves e com defeitos gravíssimos. As inflorescências distribuídas nas classes $\mathrm{C} 1$, $\mathrm{C} 2$ ou $\mathrm{C} 3$, se enquadram nos padrões estabelecidos para 
venda. Porém, seguindo os mesmos parâmetros, aquelas distribuídas nas classes C4 e C5 seriam descartadas, pois apresentavam um elevado número de defeitos inaceitáveis pelo mercado, como manchas, coloração desbotada e outros, apesar de terem sido colhidas no ponto de colheita estabelecido.

Além da avaliação quanto ao padrão de qualidade ornamental do atacado com base nas características descritas para as classes $\mathrm{C}$, a planilha de avaliação incluiu os dados de aceitação para compra das inflorescências no varejo, nas classes A ("gostei" - A1= muito; $\mathrm{A} 2=$ médio; e $\mathrm{A} 3=$ pouco) e B ("compraria" - B1= sim; B2= não). As inflorescências foram analisadas por cinco avaliadores que se posicionaram como consumidores no varejo.

Os resultados foram avaliados por intervalode confiança, considerando o nível de significância de 5\%.

\section{RESULTADOS E DISCUSSÃO}

Na grande maioria dos dimensionamentos das amostras realizados, a amostra utilizada foi representativa de uma população infinita de plantas para o nível de significância e o desvio estabelecido no material e métodos (Tabelas 3 e 4), sendo os resultados, então, considerados conclusivos para as espécies $H$. bihai $H$. stricta.

De acordo com a avaliação qualitativa, segundo a distribuição das inflorescências de $H$. bihai para venda no atacado (Classe C), não foram encontradas diferenças significativas entre os tratamentos, exceto para as inflorescências da classe C4 (inflorescências descartadas), cuja maior proporção corresponde àquelas obtidas no tratamento sem adubação (Tabela 3). A qualidade das inflorescências não foi afetada quando as plantas foram submetidas à adubação química ou orgânica.

Sendo assim, levando-se em consideração a busca por uma agricultura autossustentável, o cultivo de $H$. bihai pode ser realizado com êxito, no que se refere à produção de inflorescências de elevada qualidade, apenas com insumos orgânicos, compostos por elementos cuja eficácia já tem sido comprovada (OLIVEIRA et al., 2006b).

Cabe ressaltar que em $H$. bihai o tratamento químico produziu um maior número de inflorescências (Tabela 3). Esse comportamento, possivelmente, decorre de diferenças na velocidade de disponibilização dos nutrientes, que é maior para o adubo mineral. Todavia, estudos relacionados com o tipo de adubação, as doses, a dinâmica de decomposição e absorção, bem como com os efeitos nutricionais dos adubos fornecidos poderiam elucidar alguns questionamentos e otimizar o manejo desta espécie.

$\mathrm{Na}$ avaliação qualitativa das inflorescências, utilizando critérios subjetivos de aceitação para compra (Classes A e B), não foram encontradas diferenças significativas entre os tratamentos testados (Tabela 4).

De modo geral, os bons resultados obtidos em termos qualitativos para a $H$. bihai cultivada até mesmo sem adubação podem estar relacionados às características do solo utilizado para o cultivo. OLIVEIRA al. (2006a), avaliando a produção de Heliconia bihai em solo com características químicas inferiores ${ }^{(6)}$ ao utilizado na presente pesquisa, concluíram que, em condições de baixa fertilidade do solo, a adubação química e/ou orgânica desempenha papel importante na produção de flores.

Para $H$. stricta, não foram encontradas diferenças significativas quanto à distribuição das inflorescências, nas classes de qualidade do atacado (Classe $\mathrm{C}$ ), em nenhum dos tratamentos testados, exceto para a classe C5, cuja maior proporção de inflorescências de $H$. stricta para o descarte foi produzida pelo tratamento químico (Tabela 3). Além disso, o tratamento químico não teve inflorescências classificadas em $\mathrm{C} 1$.

LAMAS (2001) recomenda, de forma generalizada, três a quatro aplicações por ano de $150 \mathrm{~g}$ por cova da fórmula N-P-K 15-15-15, afirmando não afetar a qualidade floral. Porém, os dados obtidos na presente pesquisa, utilizando uma dosagem do nutriente $\mathrm{N}$ superior em 2,5 g ao recomendado por este autor e doses de $\mathrm{P}$ e $\mathrm{K}$, respectivamente, inferiores, em cerca de 42 e $45 \%$, mostraram que a qualidade das inflorescências em $H$. stricta foi prejudicada somente no tratamento químico, embora o tratamento orgânico tenha recebido uma dosagem de N-P-K por cova, a cada aplicação, superior à citada por este mesmo autor ( $42 \mathrm{~g}$ de N, $28 \mathrm{~g}$ de $\mathrm{P}$ e $18 \mathrm{~g}$ de K). Neste caso, possivelmente alguns fatores como a velocidade de disponibilização dos nutrientes e a melhoria na capacidade de retenção de umidade do solo, proporcionada por adubos orgânicos, favoreceram a qualidade das inflorescências produzidas pelo tratamento orgânico em $H$. stricta. Todavia, para $H$. bihai, o tratamento com adubação química proporcionou maior produtividade e melhor qualidade das inflorescências.

Cabe ressaltar que LAMAS (2001) não faz referência às condições de solo e que o solo utilizado na presente pesquisa apresentava alto teor de $\mathrm{K}$, não devendo este ter sido um fator de restrição, o que também é corroborado pela qualidade da produção do tratamento testemunha de H. stricta.

Embora o aspecto visual das plantas do tratamento químico observado na área experimental mostrasse um desenvolvimento vegetativo vigoroso, possivelmente a adubação química para $H$. stricta tenha favorecido apenas o intenso crescimento vegetativo e o acúmulo de biomassa em detrimento do florescimento. Assim, a adubação química, nessa espécie, reduziu a produção de inflorescências, e as produzidas foram de baixa qualidade não sendo enquadradas no padrão ornamental para venda no atacado.

Estes resultados confirmam diferenças na resposta à adubação dentro de um mesmo gênero para espécies diferentes, ressaltando a importância de estudos aprofundados sobre a recomendação de adubação para helicônias, de modo a evitar o uso de fórmulas generalizadas e, consequentemente, o impacto negativo que estas fórmulas possam exercer sobre a produção comercial de flores, em que a busca pela qualidade deve ser um dos fatores prioritários.

$\mathrm{Na}$ avaliação qualitativa das inflorescências de $H$.

\footnotetext{
(6) QLIVEIRA al. (2006a)- características químicas na camada de 0 - $20 \mathrm{~cm}$ da área experimental: pH 4,6; $10,7 \mathrm{~g} \mathrm{~kg}^{-1}$ de M. O.; $2 \mathrm{mg} \mathrm{kg}{ }^{-1}$ de P; $19 \mathrm{mg}$ $\mathrm{kg}^{-1}$ de $\mathrm{K} ; 1,6 \mathrm{cmol}_{\mathrm{c}} \mathrm{kg}^{-1}$ de $\mathrm{Ca}+\mathrm{Mg}$ e 3,6 $\mathrm{cmol}_{\mathrm{c}} \mathrm{kg}^{-1}$ de $\mathrm{H}+\mathrm{Al}$.
} 
stricta, adotando critérios subjetivos de aceitação para compra (Classes A e B), o tratamento orgânico foi significativamente superior aos tratamentos químico e sem adubação para a classe A1. As inflorescências produzidas sem adubação foram superiores àquelas produzidas sob os demais tratamentos na classe $\mathrm{A} 2$, porém, não foram encontradas diferenças significativas entre os três tratamentos testados para a classe A3 (Tabela 4).

As inflorescências produzidas pelo tratamento orgânico e sem adubação não diferiram entre si para as classes B1 e B2. Aquelas produzidas sob adubação química foram inferiores às demais (Tabela 4). Observa-se que, além do pequeno número de inflorescências emitidas pelo tratamento químico, 93\% delas não seriam compradas de acordo com a opinião dos avaliadores. Tal resultado vem corroborar a sentença de descarte, pré-definida para hastes florais, cujas características se encontram distribuídas nas classes $\mathrm{C} 4$ e $\mathrm{C} 5$, por apresentarem uma quantidade inaceitável de defeitos pelo mercado consumidor. Antes da avaliação de aceitação da compra no varejo, $86 \%$ das inflorescências de $H$. stricta produzidas com adubação química foram destinadas ao descarte, por terem sido classificadas 7\% em C4 e 79\% em C5.

A qualidade das inflorescências tem sido apontada como um importante fator para expansão e consolidação, nacional e internacional, do setor da floricultura de corte, sendo verificado que as exigências do consumidor final são maiores e, portanto, há riscos mais elevados de não haver aceitabilidade do produto brasileiro se não forem seguidos padrões internacionais de qualidade e cuidados pós-colheita (ANEFALOS e FILHO, 2007).

\section{CONCLUSÕES}

No cultivo de $H$. bihai, tanto a adubação química, como a orgânica contribuíram diretamente para a produção de inflorescências com melhor qualidade.

H. stricta teve as inflorescências de melhor qualidade produzidas sem adubação, nas condições de solo da presente pesquisa.

\section{REFERÊNCIAS}

ANEFAlOS, L. C. \& FILHO, J. V. C. Avaliação do processo de exportação na cadeia de flores de corte utilizando o modelo insumo-produto. Revista Brasileira de Economia, Rio de Janeiro v. 61 n. 2, p. 153-173, 2007. BERRY, F. \& KRESS, W. J. Heliconia, an identification guide. 1 ed., Washington, 1991, 334p.

BROSCHAT, T. K., DONSELMAN, H. M., WILL, A. A."Andromeda" and "Golden Torch" heliconias. Hortscience, Alexandria, v.19 n.5, p. 736 - 737, 1984.
BROSCHAT, T. K., DONSELMAN, H. M. Production and post harvest culture of Heliconia psittacorum flowers in South Florida. Proceedings of Florida State Horticultural Society, Tallahasse, v. 96, p. 272 - 273. 1983.

CASTRO, A. C. R. de, et. al. Teores de macronutrientes em plantas de helicônia 'Golden Torch' submetidas a estresse nutricional. In: CONGRESSO BRASILEIRO DE FLORICULTURA E PLANTAS ORNAMENTAIS, 16., CONGRESSO BRASILEIRO DE CULTURA DE TECIDOS DE PLANTAS, 3., SIMPÓSIO DE PLANTAS ORNAMENTAIS NATIVAS, 1., Goiânia, GO. Resumos..., Goiânia: UFG, 2007. (CDROM).

CASTRO, C. E. F. Helicônias como flores de corte; adequação de espécie e tecnologia pós-colheita. Piracicaba: ESALQ-USP, 1993, 191p. Tese (Doutorado em Fitotecnia).

CASTRO, C. E. F. Heliconia para exportação; aspectos técnicos da produção. Brasília: EMBRAPA, Ministério da Agricultura, do Abastecimento e da Reforma Agrária, Secretaria de Desenvolvimento Rural, Frupex, 1995, 44p.

CASTRO, C. E. F. \& GRAZIANO, T. T. Espécies do gênero Heliconia (Heliconiaceae) no Brasil. Horticultura Ornamental, Campinas, v.3, n.2, p.10 - 14, 1997.

IBRAFLOR, Informativo Ibraflor, ano 7, v. 23., Março, 2001.

IBRAFLOR. Padrão Ibraflor de qualidade. Campinas: Estúdio 66. Publicidade \& Marketing, 2000. 87p.

LAMAS, A. M. Floricultura tropical: técnicas de cultivo. Maceió, Alagoas: Edição SEBRAE - Série Agronegócios, 2001, 58p.

MIRANDA EE de, GOMES, EG. \& GUIMARÃES M. Mapeamento e estimativa da área urbanizada do Brasil com base em imagens orbitais e modelos estatísticos. Campinas: Embrapa Monitoramento por Satélite. 2005. Disponível em: <http://www.urbanizacao.cnpm.embrapa. br>. Acesso em: 6 dez. 2006.

OLIVEIRA, R. F. de, et. al. Comunicado Técnico, $\mathrm{n}^{\circ}$ 166: Produção de flores de Heliconia bihai com adubação mineral e orgânica. Embrapa, Belém - PA. Dezembro, 2006a.

OLIVEIRA, R. F. de, et. al. Comunicado Técnico, $\mathrm{n}^{\circ}$ 171: Efeito de cama de frango na produção de flores de Heliconia bihai. Embrapa, Belém - PA. Dezembro, 2006b. 
Tabela 1. Médias mensais de temperatura máxima (Tmáx) e mínima (Tmín), umidade relativa do ar (UR) e precipitação total (PP), observadas na estação meteorológica da Estação Experimental de Campos - Pesagro, em Campos dos Goytacazes - RJ

Table 1. Mean monthly maximum temperature (Tmax) and minimum (Tmin), relative humidity (UR) and total precipitation $(P P)$, observed at the weather station at the Experimental Station of Campos - Pesagro, in Campos dos Goytacazes - RJ

\begin{tabular}{|c|c|c|c|c|}
\hline Mês/ano & Tmáx & Tmín & UR & PP \\
\hline $\mathrm{mar} / 04$ & 31,77 & 20,75 & 72,70 & 173,30 \\
\hline $\mathrm{abr} / 04$ & 30,20 & 20,20 & 84,00 & 105,30 \\
\hline mai/04 & 27,60 & 17,60 & 80,70 & 56,50 \\
\hline jun/04 & 26,50 & 15,90 & 81,20 & 32,50 \\
\hline $\mathrm{jul} / 04$ & 24,60 & 15,40 & 82,50 & 84,10 \\
\hline ago/04 & 25,90 & 15,60 & 79,10 & 13,90 \\
\hline set/04 & 28,60 & 17,30 & 75,40 & 7,90 \\
\hline out/04 & 27,60 & 18,80 & 77,80 & 71,20 \\
\hline nov/04 & 28,80 & 20,00 & 77,30 & 80,60 \\
\hline $\mathrm{dez} / 04$ & 29,70 & 21,30 & 84,80 & 191,50 \\
\hline $\mathrm{jan} / 05$ & 30,40 & 21,80 & 81,90 & 224,00 \\
\hline $\mathrm{fev} / 05$ & 31,30 & 21,10 & 78,50 & 58,80 \\
\hline $\operatorname{mar} / 05$ & 31,20 & 21,80 & 82,60 & 159,70 \\
\hline $\mathrm{abr} / 05$ & 30,80 & 20,60 & 81,60 & 54,70 \\
\hline mai/05 & 28,00 & 18,60 & 82,00 & 94,60 \\
\hline jun/05 & 27,20 & 17,00 & 85,40 & 75,80 \\
\hline jul/05 & 25,10 & 15,50 & 82,80 & 57,50 \\
\hline ago/05 & 28,10 & 16,80 & 80,20 & 5,50 \\
\hline set/05 & 25,70 & 18,10 & 82,40 & 128,70 \\
\hline out $/ 05$ & 29,90 & 20,00 & 78,00 & 38,60 \\
\hline nov/05 & 27,20 & 19,60 & 83,80 & 219,10 \\
\hline $\mathrm{dez} / 05$ & 28,60 & 20,10 & 80,30 & 250,80 \\
\hline $\mathrm{jan} / 06$ & 31,40 & 22,63 & 83,00 & 133,30 \\
\hline $\mathrm{fev} / 06$ & 33,50 & 23,43 & 77,30 & 64,65 \\
\hline $\mathrm{mar} / 06$ & 31,90 & 22,20 & 78,30 & 49,30 \\
\hline $\mathrm{abr} / 06$ & 29,50 & 20,10 & 80,30 & 83,80 \\
\hline mai/06 & 26,90 & 16,50 & 74,50 & 14,20 \\
\hline jun/06 & 25,80 & 15,60 & 76,80 & 28,30 \\
\hline jul/06 & 27,30 & 14,30 & 79,10 & 15,70 \\
\hline ago/06 & 27,30 & 16,80 & 78,30 & 29,20 \\
\hline set/06 & 26,20 & 17,00 & 76,60 & 42,20 \\
\hline
\end{tabular}


Tabela 2. Padrão estabelecido para avaliação da qualidade ornamental de inflorescências de helicônias no atacado Table 2. Pattern established for evaluating the quality of ornamental heliconia flowers wholesale

\section{CLASSE C DESCRIÇÃO DA INFLORESCÊNCIA}

Ereta sem manchas, cor intensa e brilhante

Ereta sem manchas, cor intensa e brilhante, bráctea terminal torta

C1 Ereta sem manchas, cor intensa e brilhante, primeira bráctea grande e verde

Ereta sem manchas, cor intensa e brilhante, bráctea terminal torta, primeira bráctea grande e verde

Torta sem manchas, cor intensa e brilhante

$\mathrm{C} 2$

Torta sem manchas, cor intensa e brilhante, bráctea terminal torta

Torta sem manchas, cor intensa e brilhante, primeira bráctea grande e verde

Torta sem manchas, cor intensa e brilhante, bráctea terminal torta, primeira bráctea grande e verde

Ereta com manchas, cor intensa e brilhante

C3

Ereta com manchas, cor intensa e brilhante, bráctea terminal torta

Ereta com manchas, cor intensa e brilhante, primeira bráctea grande e verde

Ereta com manchas, cor intensa e brilhante, bráctea terminal torta, primeira bráctea grande e verde

Ereta com manchas, cor desbotada

$\mathrm{C} 4$

Ereta com manchas, cor desbotada, bráctea terminal torta

Ereta com manchas, cor desbotada, primeira bráctea grande e verde

Ereta com manchas, cor desbotada, bráctea terminal torta, primeira bráctea grande e verde

Torta com manchas, cor intensa e brilhante

Torta com manchas, cor intensa e brilhante, bráctea terminal torta

Torta com manchas, cor intensa e brilhante, primeira bráctea grande e verde

Torta com manchas, cor intensa e brilhante, bráctea terminal torta, primeira bráctea grande e

C5 verde

Torta com manchas, cor desbotada

Torta com manchas, cor desbotada, bráctea terminal torta

Torta com manchas, cor desbotada, primeira bráctea grande e verde

Torta com manchas, cor desbotada, bráctea terminal torta, primeira bráctea grande e verde 
Tabela 3. Proporção das amostras e intervalos de confiança $(p>0,05)$ para a proporção da população de inflorescências de H. bihai e H. stricta, colhidas, respectivamente, de nov./2004 a set./2006 e de fev./ 2005 a jun./2006, distribuídas nas classes C1(inflorescências sem defeitos), C2 (inflorescências com poucos defeitos), C3 (inflorescências com defeitos medianos), C4 (inflorescências com defeitos graves) e C5 (inflorescências com defeitos gravíssimos), referentes ao padrão ornamental para venda no atacado, cultivadas sob adubação química (Tratamento 1), orgânica (Tratamento 2) e sem adubação (Tratamento 3), em Campos dos Goytacazes - RJ

Table 3. Proportion of samples and confidence intervals $(p>0,05)$ for the proportion of population of inflorescences of $\underline{H}$. bihai and H. stricta, harvested, respectively, of the nov./2004 to set./2006 and of feb. / 2005 to jun./2006, distributed in classes C1 (inflorescences without defects), C2 (inflorescences with few defects), C3 (inflorescences with median defects), C4 (inflorescences with serious defects) and C5 ((inflorescences with very serious defects), for the ornamental pattern for wholesale, grown under chemical fertilization (treatment 1), organic (treatment 2) and without fertilization (treatment 3), in Campos dos Goytacazes - RJ

\begin{tabular}{|c|c|c|c|c|c|c|c|}
\hline \multirow[b]{2}{*}{ Variável } & \multirow[b]{2}{*}{ Tratamento } & \multicolumn{3}{|c|}{ Heliconia bihai } & \multicolumn{3}{|c|}{ Heliconia stricta } \\
\hline & & $\begin{array}{c}\mathrm{N}^{\mathrm{o}} \mathrm{de} \\
\text { Observações }\end{array}$ & $\begin{array}{l}\text { Proporção } \\
\text { Média }\end{array}$ & $\begin{array}{l}\text { Intervalo de } \\
\text { Confiança } \\
( \pm)\end{array}$ & $\begin{array}{c}\mathrm{N}^{\mathrm{o}} \text { de } \\
\text { Observações }\end{array}$ & $\begin{array}{l}\text { Proporção } \\
\text { Média }\end{array}$ & $\begin{array}{c}\text { Intervalo de } \\
\text { Confiança }( \pm)\end{array}$ \\
\hline \multirow{3}{*}{$\mathrm{C} 1$} & 1 & 122 & 0,38 & 0,09 & 14 & $\ldots \ldots$ & $\ldots \ldots$ \\
\hline & 2 & 82 & 0,46 & 0,11 & 45 & 0,18 & 0,12 \\
\hline & 3 & 81 & 0,27 & 0,10 & 83 & 0,36 & 0,11 \\
\hline \multirow{3}{*}{$\mathrm{C} 2$} & 1 & 122 & 0,20 & 0,07 & 14 & 0,07 & 0,15 \\
\hline & 2 & 82 & 0,12 & 0,07 & 45 & 0,20 & 0,12 \\
\hline & 3 & 81 & 0,14 & 0,08 & 83 & 0,24 & 0,09 \\
\hline \multirow{3}{*}{$\mathrm{C} 3$} & 1 & 122 & 0,21 & 0,07 & 14 & 0,07 & 0,15 \\
\hline & 2 & 82 & 0,17 & 0,08 & 45 & 0,22 & 0,13 \\
\hline & 3 & 81 & 0,24 & 0,10 & 83 & 0,08 & 0,06 \\
\hline \multirow{3}{*}{$\mathrm{C} 4$} & 1 & 122 & 0,02 & 0,03 & 14 & 0,07 & 0,15 \\
\hline & 2 & 82 & 0,02 & 0,03 & 45 & 0,16 & 0,11 \\
\hline & 3 & 81 & 0,15 & 0,08 & 83 & 0,07 & 0,06 \\
\hline \multirow{3}{*}{ C5 } & 1 & 122 & 0,19 & 0,07 & 14 & 0,79 & 0,25 \\
\hline & 2 & 82 & 0,23 & 0,09 & 45 & 0,27 & 0,13 \\
\hline & 3 & 81 & 0,20 & 0,09 & 83 & 0,24 & 0,09 \\
\hline
\end{tabular}

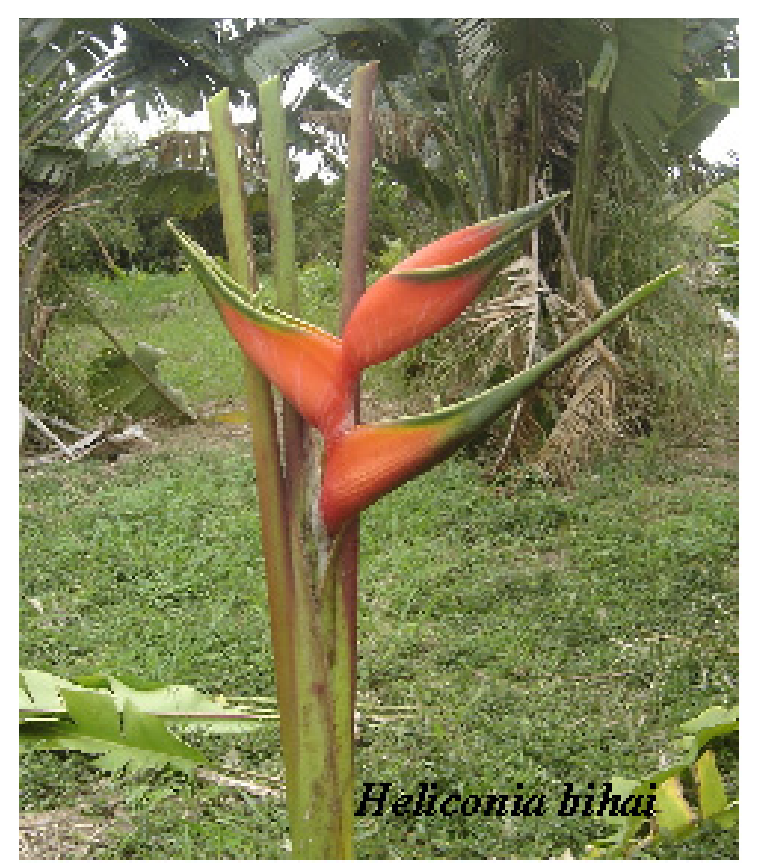

Figura 1. Ponto de colheita.

Figure 1. Point of harvest. 
Tabela 4. Proporção das amostras e intervalos de confiança $(\mathrm{p}>0,05)$ para a proporção da população de inflorescências de H. bihai e H. stricta, colhidas, respectivamente, de nov./2004 a set./2006 e de fev./ 2005 a jun./2006, aceitas de acordo com os critérios estabelecidos no varejo, nas classes A1 ("gostei" = muito), A2 ("gostei" = médio) e A3 ("gostei" = pouco); B1 ("compraria" = sim) e B2 ("compraria" = não), cultivadas sob adubação química (Tratamento 1), orgânica (Tratamento 2) e sem adubação (Tratamento 3), em Campos dos Goytacazes - RJ

Table 4. Proportion of samples and confidence intervals $(p>0,05)$ for the proportion of population of inflorescences of $\underline{H}$. bihai and $\underline{H}$. stricta, harvested, respectively, of the nov./2004 to set./2006 and of feb. / 2005 to jun./2006, accepted according to the criteria in retail, in classes A1 ("liked" = very), A2 ("liked" = middle) and A3 ("liked" = little); B1 ("will buy" = yes) and B2 ("Will buy" = no), grown under chemical fertilization (treatment 1), organic (treatment 2) and without fertilization (treatment 3), in Campos dos Goytacazes - RJ

\begin{tabular}{|c|c|c|c|c|c|c|c|}
\hline \multirow[b]{2}{*}{ Variável } & \multirow[b]{2}{*}{ Tratamento } & \multicolumn{3}{|c|}{ Heliconia bihai } & \multicolumn{3}{|c|}{ Heliconia stricta } \\
\hline & & $\begin{array}{c}\mathrm{N}^{\mathrm{o}} \mathrm{de} \\
\text { Observações }\end{array}$ & $\begin{array}{l}\text { Proporção } \\
\text { Média }\end{array}$ & $\begin{array}{l}\text { Intervalo de } \\
\text { Confiança } \\
( \pm)\end{array}$ & $\begin{array}{c}\mathrm{N}^{\mathrm{o}} \text { de } \\
\text { Observações }\end{array}$ & $\begin{array}{l}\text { Proporção } \\
\text { Média }\end{array}$ & $\begin{array}{l}\text { Intervalo de } \\
\text { Confiança } \\
( \pm)\end{array}$ \\
\hline \multirow{3}{*}{ A1 } & 1 & 122 & 0,48 & 0,09 & 14 & 0,07 & 0,15 \\
\hline & 2 & 82 & 0,43 & 0,11 & 45 & 0,44 & 0,15 \\
\hline & 3 & 81 & 0,35 & 0,11 & 83 & 0,13 & 0,07 \\
\hline \multirow{3}{*}{ A2 } & 1 & 122 & 0,13 & 0,06 & 14 & 0,07 & 0,15 \\
\hline & 2 & 82 & 0,20 & 0,01 & 45 & 0,02 & 0,04 \\
\hline & 3 & 81 & 0,20 & 0,09 & 83 & 0,19 & 0,09 \\
\hline \multirow{3}{*}{ A3 } & 1 & 122 & 0,39 & 0,09 & 14 & 0,86 & 0,21 \\
\hline & 2 & 82 & 0,38 & 0,11 & 45 & 0,53 & 0,15 \\
\hline & 3 & 81 & 0,46 & 0,11 & 83 & 0,67 & 0,10 \\
\hline \multirow{3}{*}{ B1 } & 1 & 122 & 0,61 & 0,09 & 14 & 0,07 & 0,15 \\
\hline & 2 & 82 & 0,60 & 0,11 & 45 & 0,47 & 0,15 \\
\hline & 3 & 81 & 0,51 & 0,11 & 83 & 0,33 & 0,10 \\
\hline \multirow{3}{*}{$\mathrm{B} 2$} & 1 & 122 & 0,39 & 0,09 & 14 & 0,93 & 0,15 \\
\hline & 2 & 82 & 0,40 & 0,11 & 45 & 0,53 & 0,15 \\
\hline & 3 & 81 & 0,49 & 0,11 & 83 & 0,67 & 0,10 \\
\hline
\end{tabular}

